\title{
ANALISIS TINGKAT KEPUASAN PELANGGAN PRODUK AIR MINUM DALAM KEMASAN (AMDK) AYIA CUP 240 ML MENGGUNAKAN METODE QUALITY FUNCTION DEPLOYMENT (QFD)
}

\author{
Gamindra Jauhari1 ${ }^{1}$, Rizki Naziah Lubis ${ }^{2}$ \\ Program Studi Teknik Industri, Sekolah Tinggi Teknologi Industri \\ email: gamindra_113@yahoo.com,
}

\begin{abstract}
Abstrak: Terjadinya persaingan yang semakin ketat pada industri Air Minum Dalam Kemasan (AMDK) terutama produk lokal, membuat pelanggan lebih selektif dalam memilih produk yang sesuai dengan keinginan dan kebutuhannya. PT. Gunung Naga Mas adalah perusahaan milik swasta yang memproduksi AMDK merek AYIA, menjadikan kepuasan pelanggan sebagai prioritas utamanya. Penelitian ini dilakukan untuk menganalisis kepuasan pelanggan dengan menggunakan metode Quality Function Deployment (QFD). Tujuan penelitian ini adalah mengetahui sejauhmana tingkat kepuasan pelanggan terhadap AMDK merek AYIA $240 \mathrm{ml}$ dan mengetahui urutan tingkatan prioritas karakteristik secara teknik untuk meningkatkan kualitas AMDK merek AYIA $240 \mathrm{ml}$. Hasil dari penelitian ini menunjukkan bahwa tingkat kepuasan pelanggan adalah 3,4 (puas), sedangkan urutan tingkatan prioritas karakteristik teknik adalah sanitasi dan cleaning (18,4\%), Statistical Process Control (SPC) $(18,4 \%)$, penyebaran agen secara merata $(17,8 \%)$, pemilihan bahan baku $(15,2 \%)$, penelitian dan pengembangan $(11,85 \%)$, hygiene $(6,14 \%)$, Hazard Analysis Critical Crisis Point (HACCP) (6,14\%), dan terakhir promosi (5,95\%). Diharapkan PT. Gunung Naga Mas melakukan perbaikan dan evaluasi terhadap kualitas produk karena masih adanya kesenjangan ( $\mathrm{gap}$ ) dari penilaian konsumen, meskipun perusahaan telah melakukan perbaikan secara keseluruhan yaitu sebesar $53,8 \%$.
\end{abstract}

Kata Kunci: Air Minum Dalam Kemasan (AMDK), kepuasan pelanggan, Quality Function Deployment (QFD).

Abstract: The increasingly fierce competition in the Bottled Drinking Water (AMDK) industry, especially local products, makes customers more selective in choosing products that suit their wants and needs. PT. Gunung Naga Mas is a privately owned company that produced AMDK from the AYIA brand, making customer satisfaction its top priority. This research was conducted to analyze customer satisfaction using the Quality Function Deployment (QFD) method. The purpose of this study was to determine the extent of customer satisfaction with the brand drinking water bottoms of AYIA $240 \mathrm{ml}$ and to know the order of priority levels of the technical characteristics to improve the quality of bottled water of the AYIA brand $240 \mathrm{ml}$. The results of this study showed that the level of customer satisfaction was 3.4 (satisfied), while the order priority levels of engineering characteristics are sanitation and cleaning (18.4\%), Statistical Process Control (SPC) (18.4\%), distribution of agents evenly (17.8\%), selection of raw materials (15.2\%), research and development (11.85\%), hygiene (6.14\%), Hazard Analysis Critical Crisis Point (HACCP) (6.14\%), and finally promotion (5.95\%). It is expected that PT. Gunung Naga Mas makes improvements and evaluations of product quality because there are still gaps in consumer ratings, even though the company has made an overall improvement of $53.8 \%$.

Keywords: Bottled Drinking Water (AMDK), customer satisfaction, Quality Function Deployment (QFD). 


\section{PENDAHULUAN}

Perkembang dengan teknologi yang sangat cepat mengakibatkan daur hidup produk semakin pendek. Untuk itu, perusahaan dituntut harus melakukan inovasi guna memenuhi keinginan dan kebutuhan pelanggan yang beragam sehingga dicapainya tingkat kepuasan pelanggan. Disamping itu, setiap perusahaan dituntut untuk melakukan inovasi terhadap produk yang dihasilkanya agar mampu bersaing, terutama pada perusahaan yang sejenis. Salah satu industri yang akhir-akhir ini mengalami perkembangan yang cukup pesat adalah industri penyedia air minum dalam kemasan (AMDK).

PT. Gunung Naga Mas merupakan perusahaan swasta yang menghasilkan air minum dalam kemasana (AMDK), yang berdasarkan ketentuan secara nasional telah memenuhi SNI 01-3553-2015. Pengunaan air baku yang menjadi sumber utama diperoleh pada sumur dengan kedalaman 100 meter, Perusahaan ini menghasilkan AMDK terdiri dari bermacam-macam jenis ukuran kemasan yaitu gelas atau cup $240 \mathrm{ml}$, botol $380 \mathrm{ml}, 660$ $\mathrm{ml}$, dan botol $1500 \mathrm{ml}$ serta ukuran gallon dengan merek AYIA. Ukuran kemasan produk yang paling dominan jumlah hasil produksinya yaitu kemasan gelas atau cup $240 \mathrm{ml}$. Untuk produk kemasan ini, bersaing secara ketat dengan produk local lainnya. Oleh karena itu perusahaan dituntut untuk lebih memperhatikan keinginan dan kebutuhan pelanggan sehingga pelanggan mendapatkan kepuasan.

$$
\text { Kepuasan pelanggan terhadap }
$$

pemenuhan kebutuhannya dapat diketahui dengan mengunakan daftar terstruktur yang dilakukan melalui penelitian pasar seperti kuesioner dan metode Quality Function Deployment (QFD). QFD dapat didefinisikan sebagai analisis terhadap produk dan proses secara sistemis yang bertujuan agar kemampuan produk dan jasa memenuhi karakteristik penting sesuai keinginan dan kebutuhan pelanggan (Emmalia, 2008).

\section{METODE PENELITIAN}

Penelitian ini menggunakan metode deskriptif kuantitatif yaitu penelitian yang digunakan untuk meneliti populasi atau sampel tertentu, teknik pengambilan sampel pada umumnya dilakukan secara random (Sugiyono, 2013).
Populasi pada penelitian ini adalah seluruh konsumen produk Ayia $240 \mathrm{ml}$ di kota Padang. Sampel pada penelitian ini adalah konsemen Ayia $240 \mathrm{ml}$ yang mengkonsumsi Ayia pada saat penelitian dilakukan. Jadi responden yang digunakan sebesar 100 responden. Kriteria konsumen yang dijadikan responden yaitu :

1. Konsumen tersebut pernah mengkonsumsi produk Ayia minimal dua kali sehingga konsumen dapat dipastikan telah mengenal produk dan dapat menilai kualitas produk.

2. Konsumen bersedia diwawancarai atau mengisi kuisioner yang telah disediakan.

Peneliti menyebarkan beberapa kuesioner yang telah dipersiapkan untuk dibagikan kepada responden. Sebanyak 30 kuesioner pendahuluan disebarkan terlebih dahulu untuk keperluan uji validitas dan reliabilitas. 30 responden merupakan sampel minimum untuk jenis penelitian deskriptif (Risenasari,2009).

\section{HASIL DAN PEMBAHASAN}

\section{Penyebaran Kuesioner}

Penyebaran kuesioner pendahuluan atau awal dilakukan secara acak kepada para pelanggan yang mengkonsumsi produk Ayia $240 \mathrm{ml}$ berdasarkan kedekatan mereka dengan peneliti. Penyebaran kuesioner awal ini dilakukan terhadap 30 responden untuk keperluan uji validitas dan uji reliabilitas. Sedangkan penyebaran kuesioner utama dilakukan terhadap 70 responden untuk dilakukan kembali uji validitas, uji reliabilitas.

\subsection{Pengujian Kuesioner \\ 1.2.1 Uji Validitas}

Uji validasi kuisioner dilakukan dengan penyebaran kuisioner awal sebanyak 30 kuisioner awal dan 70 kuesioner utama. Hasil perhitungan uji validitas kuesioner awal memiliki nilai >0,3610 sehingga menunjukkan 12 variabel pernyataan tersebut adalah valid dan kuesioner utama memiliki nilai > 0,2352 sehingga menunjukkan 12 variabel pernyataan tersebut adalah valid.

\subsubsection{Uji Reliabilitas}

Dari hasil pengukuran kuisioner dilakukan uji reliabilitas yang menunjukkan nilai masingmasing dimensi $>0,6$ sehingga alat ukur yang 
digunakan reliabel. Nilai koefisien yang memadai menunjukkan bahwa telah mampu dipercaya sebagai alat ukur dalam penelitian.

\section{Tingkat Kepentingan Pelanggan}

Tabel 1. Rekapitulasi Nilai Tingkat Kepentingan Pelanggan

\begin{tabular}{|c|c|c|c|c|c|c|}
\hline \multirow{2}{*}{$\begin{array}{c}\text { Atribut } \\
\text { Pernyataan }\end{array}$} & \multicolumn{4}{|c|}{ Indikator Penilaian } & \multirow{2}{*}{$\begin{array}{l}\text { Jumlah } \\
\text { Responden }\end{array}$} & \multirow{2}{*}{$\begin{array}{c}\text { Tingkat } \\
\text { Kepentingan }\end{array}$} \\
\hline & 1 & 2 & 3 & 4 & & \\
\hline Kejernihan air & 0 & 0 & 8 & 92 & 100 & 3.92 \\
\hline Tidak berasa & 0 & 0 & 8 & 92 & 100 & 3.92 \\
\hline Tidak berbau & 0 & 0 & 6 & 94 & 100 & 3.94 \\
\hline Tidak berlumut & 0 & 0 & 6 & 94 & 100 & 3.94 \\
\hline Tersedia di warung kecil maupun besar & 0 & 0 & 18 & 82 & 100 & 3.82 \\
\hline Jalur distribusis sampai ke penjuru kota & 0 & 0 & 21 & 79 & 100 & 3.79 \\
\hline Harga produk lebih murah dibanding para pesaingnya & 0 & 0 & 22 & 78 & 100 & 3.78 \\
\hline Terjangkau untuk seluruh segmen pasar & 0 & 0 & 37 & 63 & 100 & 3.63 \\
\hline Ketahanan dan kekuatan kemasan/wadah & 0 & 0 & 6 & 94 & 100 & 3.94 \\
\hline Desain kemasan & 0 & 2 & 14 & 84 & 100 & 3.82 \\
\hline Ramah lingkungan & 0 & 0 & 14 & 86 & 100 & 3.86 \\
\hline Nyaman digunakan (ergonomis) & 0 & 0 & 14 & 86 & 100 & 3.86 \\
\hline
\end{tabular}

Atribut persyaratan dari produk Ayia 240 $\mathrm{ml}$ yang dianggap penting oleh responden (memiliki nilai tingkat kepentingan sama dengan atau lebih dari 3), yaitu kejernihan air, tidak berasa, tidak berbau, tidak berlumut, tersedia diwarung kecil maupun besar, jalur distribusi sampai ke seluruh kota, harga produk lebih murah dibandingkan para pesaingnnya, terjangkau untuk seluruh segmen pasar, ketahanan dan kekuatan kemasan atau wadah, desain kemasan, ramah lingkungan, nyaman digunakan (ergonomis).

\section{Tingkat Kepuasan Pelanggan}

Tabel 2. Rekapitulasi Nilai Tingkat Kepuasan Pelanggan

\begin{tabular}{lcccccc}
\hline \multirow{2}{*}{$\begin{array}{c}\text { Atribut } \\
\text { Pernyataan }\end{array}$} & \multicolumn{4}{c}{ Indikator Penilaian } & Jumlah & Tingkat \\
\cline { 2 - 6 } \multicolumn{1}{c}{} & 1 & 2 & 3 & 4 & Responden & Kepuasan \\
\hline Kejernihan air & 0 & 12 & 28 & 60 & 100 & 3.48 \\
Tidak berasa & 0 & 6 & 30 & 64 & 100 & 3.58 \\
Tidak berbau & 0 & 16 & 35 & 49 & 100 & 3.33 \\
Tidak berlumut & 0 & 20 & 9 & 71 & 100 & 3.51 \\
Tersedia di warung kecil maupun besar & 0 & 2 & 58 & 40 & 100 & 3.38 \\
Jalur distribusi sampai ke penjuru kota & 0 & 6 & 64 & 30 & 100 & 3.24 \\
Harga produk lebih murah dibanding para pesaingnya & 0 & 8 & 57 & 35 & 100 & 3.27 \\
Terjangkau untuk seluruh segmen pasar & 0 & 9 & 60 & 31 & 100 & 3.22 \\
Ketahanan dan kekuatan kemasan/wadah & 0 & 2 & 35 & 63 & 100 & 3.61 \\
Desain kemasan & 0 & 7 & 32 & 61 & 100 & 3.54 \\
Ramah lingkungan & 0 & 3 & 33 & 64 & 100 & 3.61 \\
Nyaman digunakan (ergonomis) & 0 & 14 & 15 & 71 & 100 & 3.57 \\
\hline
\end{tabular}

Pelanggan merasa puas dengan kata lain tingkat kepentingannya bernilai sama dengan 3 dan/atau lebih, terhadap persyaratan spesifik pada produk merek Ayia kemasan gelas atau cup $240 \mathrm{ml}$,

Meskipun demikian, perusahaan perlu meningkatkan kinerjanya dengan tetap memperhatikan kualitas produknya secara terus menerus, sehingga menjadi keunggulan kompetitif dibandingkan produk sejenis.

\section{Hasil Rasio Perbaikan Perusahaan}

Table 3. Rasio Perbaikan Yang Akan Dilakukan PT. Gunung Naga Mas.

\begin{tabular}{|c|c|c|c|}
\hline $\begin{array}{c}\text { Atribut } \\
\text { Pernyataan }\end{array}$ & $\begin{array}{c}\text { Target yang } \\
\text { diinginkan }\end{array}$ & $\begin{array}{l}\text { Tingkat } \\
\text { Kepuasan }\end{array}$ & $\begin{array}{c}\text { Rasio } \\
\text { Perbaikan }\end{array}$ \\
\hline Kejernihan air & 3.92 & 3.48 & 1.13 \\
\hline Tidak berasa & 3.92 & 3.58 & 1.09 \\
\hline Tidak berbau & 3.94 & 3.33 & 1.18 \\
\hline Tidak berlumut & 3.94 & 3.51 & 1.12 \\
\hline Tersedia di warung kecil maupun besar & 3.82 & 3.38 & 1.13 \\
\hline Jalur distribusi sampai ke penjuru kota & 3.79 & 3.24 & 1.17 \\
\hline Harga produk lebih murah dibanding para pesaingnya & 3.78 & 3.27 & 1.16 \\
\hline Terjangkau untuk seluruh segmen pasar & 3.63 & 3.22 & 1.13 \\
\hline Ketahanan dan kekuatan kemasan/wadah & 3.94 & 3.61 & 1.09 \\
\hline Desain kemasan & 3.82 & 3.54 & 1.08 \\
\hline Ramah lingkungan & 3.86 & 3.61 & 1.07 \\
\hline Nyaman digunakan (ergonomis) & 3.86 & 3.57 & 1.08 \\
\hline
\end{tabular}

Semakin besar nilai rasio perbaikan memberikan informasi bahwa perusahaan harus semakin cepat meningkatkan kualitas berdasarkan atribut pernyataan keinginan pelanggan dan pencapaian target perusahaan di masa datang.

\section{Karakteristik Teknik}

Karakteristik teknik ini diperoleh dari referensi dan rekomendasi dari Bapak Dedi Putra S.Si sebagai kepala bagian QA di PT. Gunung Naga Mas. Karakteristik atau persyaratan teknis dan operasional untuk diproduksi sesuai kebutuhan pelanggan adalah sebagai berikut:

Tabel 4. Karakteristik Teknik

\begin{tabular}{cl}
\hline No & \multicolumn{1}{c}{ Karakteristik Teknik } \\
\hline 1 & Pemilihan bahan baku Ayia $240 \mathrm{ml}$ \\
2 & Hygiene \\
3 & HACCP ( Hazard Analysis Critical Crisis Point) \\
4 & Sanitasi dan Cleaning \\
5 & SPC (Statistical Proses Control) \\
6 & Penelitian dan Pengembanagan \\
7 & Penyebaran agen secara merata di seluruh kota \\
8 & Promosi \\
\hline
\end{tabular}

Hubungan Kebutuhan Pelanggan dengan Karakteristik Teknik

Hubungan antara atribut kejernihan air, tidak berasa, tidak berbau dan tidak berlumut dengan karakteristik teknik HACCP (Hazard Analysis Critical Crisis Point), Hygiene, Sanitasi dan cleaning, dan Penelitian dan pengembangan. Karena keempat karakteristik tersebut saling berhubungan satu sama lain untuk menjaga dan meningkatkan mutu produk. Kemudian atribut tersedia diwarung kecil maupun besar dan jalur distribusi sampai ke 
penjuru kota ada hubungannnya dengan karakteristik teknis yaitu penyebaran agen secara merata di seluruh kota dan tersedia di warung kecil maupun besar.

Tabel 5. Matriks Hubungan Kebutuhan Pelanggan Dengan Karakteritik Teknik

\begin{tabular}{|c|c|c|c|}
\hline No & Karakteristik Teknik & Kebutuhan Konsumen & $\begin{array}{c}\text { Matriks } \\
\text { Hubungan }\end{array}$ \\
\hline \multirow{4}{*}{1} & \multirow{4}{*}{ Pemilihan bahan baku Ayia $240 \mathrm{ml}$} & Tidak berasa & 0 \\
\hline & & Ramah lingkungan & - \\
\hline & & Ketahanan dan kekuatan kemasan/wadah & - \\
\hline & & Nyaman digunakan (ergonomis) & - \\
\hline \multirow{4}{*}{2} & \multirow{4}{*}{ Hygiene } & Kejernihan air & \\
\hline & & Tidak berasa & 。 \\
\hline & & Tidak berbau & 。 \\
\hline & & Tidak berlumut & $\circ$ \\
\hline \multirow{4}{*}{3} & \multirow{4}{*}{ HАCСР (Hazard Analysis Critical Crisis Point) } & Kejernihan air & 0 \\
\hline & & Tidak berasa & 。 \\
\hline & & $\begin{array}{l}\text { Tidak berbau } \\
\text { Than }\end{array}$ & . \\
\hline & & Tidak berlumut & $\circ$ \\
\hline \multirow{4}{*}{\multicolumn{2}{|c|}{4 Sanitasi dan Cleaning }} & Kejernihan air & $\bullet$ \\
\hline & & Tidak berasa & \\
\hline & & Tidak berbau & - \\
\hline & & Tidak berlumut & - \\
\hline \multirow{5}{*}{\multicolumn{2}{|c|}{$5 \mathrm{SPC}$ (Statistical Proces Control) }} & Kejernihan air & $\cdot$ \\
\hline & & Tidak berasa & - \\
\hline & & Tidak berbau & - \\
\hline & & Tidak berlumut & - \\
\hline & & Ketahanan dan kekuatan kemasan/wadah & - \\
\hline & \multirow{6}{*}{ Penelitian dan Pengembanagan } & Harga produk lebih murah dibanding para pesaingnya & - \\
\hline & & Tidak berbau & $\circ$ \\
\hline & & Tidak berlumut & $\circ$ \\
\hline & & Ketahanan dan kekuatan kemasan/wadah & $\circ$ \\
\hline & & Desain kemasan & - \\
\hline & & Terjangkkuu untuk seluruh segmen pasar & - \\
\hline 7 & Penyebaran agen secara merata di seluruh kota & Tersedia di warung kecil maupun besar & $\dot{0}$ \\
\hline \multirow{2}{*}{\multicolumn{2}{|c|}{8 Promosi }} & $\begin{array}{l}\text { Jalur distribusis sampai ke penjuru kota } \\
\text { Tersedia di warung kecil maupun besar }\end{array}$ & \\
\hline & & $\begin{array}{l}\text { Tersedadi dr warung kecil maupun besar } \\
\text { Jalur distribusi sampai ke penjuru kota }\end{array}$ & $\circ$ \\
\hline
\end{tabular}

Nilai Prioritas Karakteristik Teknik

Tabel 6. Rekapitulasi Nilai Prioritas Karakteristik Teknik

\begin{tabular}{|c|c|c|c|c|c|c|c|}
\hline \multirow{3}{*}{ No } & \multirow{2}{*}{ Karakterisitik Teknik } & \multirow{2}{*}{ Kebutuhan Konsumen } & \multirow{2}{*}{$\begin{aligned} \begin{array}{c}\text { Nilia Mariki } \\
\text { Hubungan }\end{array} \\
\end{aligned}$} & \multirow{2}{*}{\multicolumn{3}{|c|}{ 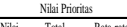 }} & \multirow{2}{*}{$\begin{array}{l}\text { Persentase } \\
\text { Prionas } \\
\end{array}$} \\
\hline & & & & Niai & & Ratarrala & \\
\hline \multirow{3}{*}{\multicolumn{2}{|c|}{1 Pemilhan bahan baklu Ayja $240 \mathrm{ml}$}} & Tidalk berkas & & 3.92 & 11.76 & \multirow{3}{*}{29.175} & \multirow{3}{*}{15.201} \\
\hline & & Ramah higktumgan & 9 & 3.86 & 3.74 & & \\
\hline & & 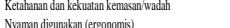 & & 3.94 & 35.46 & & \\
\hline \multirow{4}{*}{2} & \multirow{4}{*}{ Hygiene } & 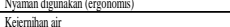 & $\frac{9}{3}$ & 3.962 & $\frac{34.74}{1176}$ & & \multirow{4}{*}{6.143} \\
\hline & & Tidakb beras & $x^{2}$ & 3.92 & 11.76 & \multirow{3}{*}{11.79} & \\
\hline & & Tididk herhau & 3 & & & & \\
\hline & & Tidak berlumut & 3 & 3.4 & 11.82 & & \\
\hline \multirow{4}{*}{\multicolumn{2}{|c|}{3 HACCP (Htharard Anulysis Chitical Crisis Point) }} & Képmihan air & Th & 3.92 & 11.76 & \multirow{4}{*}{11.79} & \multirow{4}{*}{6.143} \\
\hline & & Tidialb bersan & 3 & 3.92 & 11.76 & & \\
\hline & & Tidiak berbau & & & & & \\
\hline & & Tidakk berhumat & 3 & 3.94 & 11.82 & & \\
\hline \multirow{4}{*}{\multicolumn{2}{|c|}{4 Sanitasi dan Cleaning }} & Kéemmlhan air & 3 & 3.92 & 3528 & \multirow{4}{*}{35.37} & \multirow{4}{*}{18.429} \\
\hline & & Tidiak bersan & 9 & 3.92 & 3528 & & \\
\hline & & Tidiak berbau & & & & & \\
\hline & & Tidak berlumat & 9 & 3.94 & 35.46 & & \\
\hline \multirow{4}{*}{\multicolumn{2}{|c|}{$5 \operatorname{SPC}($ Statisistial Proces Control $)$}} & Kéemmihan air & 9 & 3.92 & 35.28 & \multirow{4}{*}{35.388} & \multirow{4}{*}{18.438} \\
\hline & & 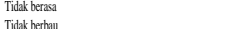 & ? & 3.92 & $\begin{array}{l}35.28 \\
3546\end{array}$ & & \\
\hline & & Tidak berlumunt & 9 & 3.94 & 35.46 & & \\
\hline & & 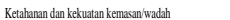 & 9 & 3.4 & 3.46 & & \\
\hline \multirow{6}{*}{\multicolumn{2}{|c|}{6 Penelitian dan Pengembanagan }} & Harga produkl lebh mural dibanding para pesingngya & 9 & 3.78 & 34,02 & \multirow{6}{*}{22.755} & \multirow{6}{*}{11.856} \\
\hline & & Tidiak berau & 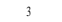 & 3.44 & 11.82 & & \\
\hline & & Tidak berlumat & 3 & 3.44 & 11.82 & & \\
\hline & & Ketalhanan dan kekvatan kemasanwwathh & 3 & 3.94 & 11.82 & & \\
\hline & & Desain kemasun & 9 & 3.82 & 3.388 & & \\
\hline & & 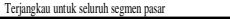 & 9 & 3.63. & ${ }^{3267}$ & & \\
\hline \multirow{2}{*}{\multicolumn{2}{|c|}{7 Penyebranan agen secara meratat dis selunh hota }} & Tersedia di warng kecil maupun besar & 9 & 3.82 & 34.38 & \multirow[t]{2}{*}{34245} & \multirow[t]{2}{*}{17.843} \\
\hline \multirow{3}{*}{\multicolumn{2}{|c|}{8 Pronowsi }} & 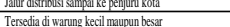 & & & & & \\
\hline & & Jalur distribus sampai ke penjuru kota & 3 & 3.79 & 11.37 & 11.415 & 5.48 \\
\hline & & Jumlah & & & & 191.9280 & 100 \\
\hline
\end{tabular}

\section{Korelasi Teknik}

Gambar 1. di bawah ini menunjukkan korelasi teknik antar karakteristik teknik yang ada.

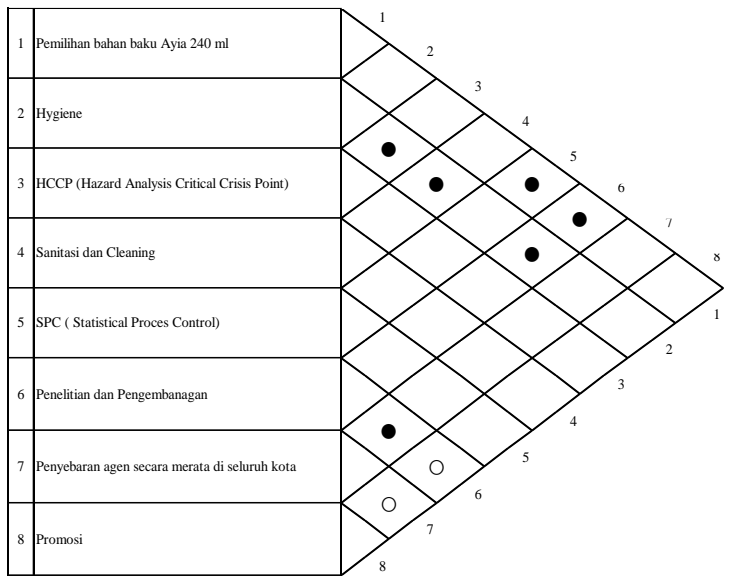

Gambar 1. Korelasi Teknik

\section{KESIMPULAN}

1. Pelanggan merasa puas terhadap AMDK merek AYIA $240 \mathrm{ml}$ yaitu dengan nilai kepuasan sebesar 3,4.

2. Urutan karakteristik teknik AMDK merek AYIA $240 \mathrm{ml}$ yaitu sanitasi \& cleaning (18,4\%), SPC (Statistical Process Control) $(18,4 \%)$, Penyebaran agen secara merata di seluruh kota $(17,8 \%)$, Pemilihanan bahan baku AYIA $240 \mathrm{ml}(15,2 \%)$, Penelitian dan Pengembangan (11,85\%), Hygiene (6,14\%), HACCP (Hazard Analysis Critical Crisis Point) (6,14\%), Promosi (5,95\%).

\section{DAFTAR PUSTAKA}

Amrina. E., dan Fajrah. N., (2015), Analisis Ketidaksesuaian Produk Air Minum Dalam Kemasan Di PT. Amanah Insanillahia, Universitas Andalas, Padang, Jurnal Optimasi Sistem Industri, Vol.14, No.1.

Dew. T. E., (2009) Kuesioner Quality Function Deployment, Universitas Kristen Maranatha Bandung, Bandung.

Ariani, Dorothea. W., (2008), Manajemen Kualitas, Penerbit Andi, Yogyakarta.

Emmalia, A., (2008), Aplikasi Metode Quality Function Deployment (QFD) Dalam Usaha Memenuhi 
Kepuasan Pelanggan Terhadap Produk Aqua Gelas 240 Ml Pada PT. Tirta Investama Pandaan, Prosiding Seminar Nasional Teknoin, Bidang Teknik Industri, Malang.

Nasution, M, N., (2005), Manajemen Mutu Terpadu (Total Quality Management), Ghalia Indonesia, Jakarta.

Risenasari, H., (2009), Penerapan Metode Quality Function Deployment (QFD) Dalam Upaya Peningkatan Kualitas Pelayanan Restoran Pringjajar Kabupaten Pemalang Jawa Tengah, IPB-Bogor.

Sitinjak, Tony., (2004), Model Matriks Konsumen Untuk Menciptakan Superior Customer Value, PT. Gramedia Pustaka Utama, Jakarta.

Sugiyono., Metodologi Penelitian Kualitatif, Kuantitatif, dan R \& D, Alfabeta, Bandung, 2013

Suwana, Rey. K., dkk, Penerapan Quality Function Deployment (Qfd) UntukMemenuhi Kepuasan Pelanggan Cv.Tirta Tamanbali Bangli, Fakultas Teknologi Pertanian, Universitas Udayana, Denpasar, 2014.

Tjiptono., dkk, Service, Quality, \& Satisfaction, ANDY, Yogyakarta, 2011.

Tutuhatunewa, A., (2010), Aplikasi Metode Quality Function Deployment Dalam Pengembangan Produk Air Minum Kemasan, Universitas Pattimura, Ambon, 2010. Jurnal Arika. Vol. 4, No. 1.

Wijaya, T., (2011), Manajemen Kualitas Jasa, Indeks, Yogyakarta.
Yuliarmi, Ni Nyoman., Riyasa, P., (2007), Analisis Faktor-Faktor Yang Mempengaruhi Kepuasan Pelanggan Terhadap Pelayanan Pdam Kota Denpasar, Universitas Udayana, Denpasar, Buletin Studi Ekonomi, Vol. 12, No. 1. 